\title{
Marginalization, Vulnerability and Economic Dynamics in COVID-19
}

\author{
Andres Felipe Valencia Rendon, ${ }^{(0)}$ Isabela Mendes Volschan, ${ }^{(0)}$ Manoella de Novais Pereira, ${ }^{(0)}$ Alessandra de \\ Freitas Pimentel, ${ }^{(1)}$ Wagner Lima Monteiro, ${ }^{(0)}$ Gláucia Maria Moraes de Oliveira ${ }^{(1)}$ \\ Universidade Federal do Rio de Janeiro, Rio de Janeiro, RJ - Brazil.
}

\begin{abstract}
COVID-19, caused by the coronavirus family SARS-CoV-2 and declared a pandemic in March 2020, continues to spread. Its enormous and unprecedented impact on our society has evidenced the huge social inequity of our modern society, in which the most vulnerable individuals have been pushed into even worse socioeconomic situations, struggling to survive.

As the pandemic continues, we witness the huge suffering of the most marginalized populations around the globe, even in developed, high-income latitudes, such as North America and Europe. That is even worse in low-income regions, such as Brazil, where the public healthcare infrastructure had already been struggling before the pandemic.

Cities with even more evident social inequity have been impacted the most, leaving the most socioeconomically disadvantaged ones, such as slum residents and black people, continuously inflating the statistics of COVID-19 sufferers.

Poverty, marginalization, and inequity have been well-known risk factors for morbidity and mortality from other diseases. However, COVID-19 has deepened our society's wound. It is up to us to heal it up. If we really care for the others and want to survive as a species, we must fight social inequity.
\end{abstract}

\section{Introduction}

One of the most disastrous diseases in human history, COVID-19, caused by the coronavirus family SARSCoV-2, continues to spread across the world, after being declared pandemic by the World Health Organization

\section{Keywords}

COVID-19, Coronavirus-19; Social Marginalization; Disaster Vulnerability; Poverty; Ethnicity and Health; Population Dynamics; Brazil. on March 11, 2020, causing 2486405 deaths worldwide. ${ }^{1}$ The rapid spread and high estimated infectivity of SARS-CoV-2 coupled with the illness severity have led to widespread shuttering of businesses and implementation of mandatory stay-at-home orders around the world, in addition to a global economic shutdown. ${ }^{2}$

The dynamics between health and inequity has been regularly present for marginalized populations worldwide. The desperate measures to stop the virus spread have had an economic impact on the most vulnerable countries and communities. ${ }^{3}$

Known before the current pandemic, a study extending from 1950 to 1991 and involving 20 developed, developing and underdeveloped countries, has revealed that the increasing prevalence of infectious diseases will not only increase human mortality and morbidity, but will result in the gradual erosion of the state capacity and increase poverty. ${ }^{4}$ The disease-induced economic decline has been found to have a negative effect on the capacity to manage financial resources, resilience, the search for responses, autonomy and legitimacy. ${ }^{5}$

Even before the COVID-19 pandemic, the balance between inequity and health has been in turmoil, with the most marginalized populations around the world being the most impacted. ${ }^{6}$ Currently, an important portion of those populations has been forced even deeper into poverty. Among other factors, this is the result of a historic confluence of social, structural, and economic inequity. ${ }^{7}$ In this phenomenon, informal workers and unemployed ones are greatly affected, and this is compounded by their precarious backgrounds..$^{8,9}$

The soaring unemployment rate seen in the pandemic and the reduced capacity to obtain goods, like food and basic resources, have pushed a large number of the global population into struggling conditions. ${ }^{10}$ 
The aggressiveness of the new virus took the international community by surprise and drove different healthcare systems in different latitudes to a nearly complete collapse.

Even highly developed countries, like the United States of America (USA), one of the biggest economies in the globe, has struggled to give its citizens the appropriate care they desperately need; and sadly, people affected by COVID-19 are counted by millions. ${ }^{11}$

The disease-related complications, rates of hospitalization and mortality are not homogeneous among the population, even within the same affected areas. New York City (NYC), with a population of 8398 748 individuals and one of the most affected cities by the new disease, has evidenced a substantial variation in the rates of COVID-19 hospitalization and death across its boroughs. Bronx, which has the highest proportion of racial/ethnic minorities, most of them living in poverty, and the lowest levels of educational attainment, had higher rates of COVID-19-related hospitalization and death than the other four boroughs of NYC, including Manhattan, which has the highest population density but the lowest rates of hospitalization and death. ${ }^{12}$ This phenomenon shows that not only the pathogen inner infective capability is important to its spread, but the social economical background of the community is of great importance for the viral spread dynamics. Early diagnosis and monitoring of patients with COVID-19 are critical to optimize individual outcomes and to prevent further community transmission. ${ }^{11}$ In NYC, 34\% and $28 \%$ of the deaths from COVID-19 occurred in Hispanic and black individuals, respectively, which represent only $29 \%$ and $22 \%$ of that city population; however, $27 \%$ of the deaths from COVID-19 occurred in white individuals, which represent $32 \%$ of the NYC population.

This phenomenon is more evident in African and Latin American latitudes, where many countries score poorly on the WASH Performance Index, which is a measure of access to abundant clean water and improved sanitation. If increased transmission due to fecal contamination is combined with climatically reduced contact transmission, the epidemiological dynamics of COVID-19 in Latin America may be fundamentally distinct from that currently observed in the Northern hemisphere. ${ }^{13,14}$

The stay-at-home policies implemented worldwide are harder to apply to underdeveloped countries like those in Latin America. Policies, such as lockdown, have a great economic impact on the general population. In
Brazil, the concept of remote work is not feasible for the great majority of the population. A local survey shows that only $27.1 \%$ of the population can work remotely, and this percentage represents people of high educational level, which in Brazil is scarce, reflecting and confirming the country's known social inequity. This scenario is even worse in the southeastern region of the country, which accounts for $42 \%$ of the Brazilian population and comprises some of the federal units with the highest demographic densities, such as São Paulo (166.23 pop/ $\mathrm{km}^{2}$ ) and Rio de Janeiro (365.23 pop/ $\left./ \mathrm{km}^{2}\right)$.

That population density and unique social dynamics have pushed the Brazilian Unified Public Health System (SUS) to its boundaries. The SUS, known as the world's biggest social health care system with more than 200 million users, has almost faced a collapse with the current pandemic. ${ }^{15,16}$ The city of Rio de Janeiro, known for its great social status breaches, has been one of the most affected. There, hospitals have been challenged to almost their healthcare limits because of the high number of patients in need for inpatient/intensive care. ${ }^{17}$

Some of the greatest threats faced by healthcare workers treating COVID-19 patients are the various difficulties of patients' access to medical institutions. In Rio de Janeiro, on average, those patients live in the city's periphery, have a low income, and, inside their own communities, deep in the slums, they have to cope with violence and segregation, in addition to a great limitation of public transportation. In our personal experience, we have seen that low baseline economic status is related to in-hospital complications and can influence in-hospital mortality. ${ }^{18,19}$ These markers of marginalization, among others, are determinants of the individual outcomes related to different clinical and social scenarios.

Marginalized communities are those excluded from mainstream social, economic, educational, and/ or cultural life. Examples of marginalized populations are groups excluded due to race, sexual orientation, age, language, physical ability, and/or immigration status. Marginalization occurs due to unequal power relationships between social groups. ${ }^{9}$

As portrayed by Rogers, "there is a distinction between inherent vulnerability, arising from one's corporeality; situational vulnerability stemming from one's personal, social, political, economic, or environmental situatedness as an individual or member of a group; and pathogenic vulnerability, emerging in sociopolitical contexts, where a pre-existing vulnerability is multiplied by oppression or injustice". ${ }^{20,21}$ 
Vulnerable groups of people are those disproportionally exposed to risk, but the composition of such groups change dynamically. ${ }^{22} \mathrm{~A}$ person not considered vulnerable at the outset of the pandemic can become vulnerable depending on the policies adopted. The risks of sudden loss of income or of access to social support have consequences difficult to estimate; in addition, identifying all those who might become vulnerable is a challenge. ${ }^{23}$

Populations are heterogeneous in composition (for example, those living with disability, people living in poverty, and racial, ethnic, sexual and gender minorities), and the intersection of those identities within an individual or group can further compound their baseline disadvantage. ${ }^{24}$ When analyzing the environmental factors of those communities, African Americans are 75\% more likely to reside in proximity to a polluting facility, like a factory or refinery, than other Americans, and, as compared to white individuals, they are exposed to a $38 \%$ more polluted air. ${ }^{25}$

Even biological risk factors for COVID-19, such as hypertension, diabetes, asthma, and obesity, can reflect environmental and sociological precipitating and contributing factors, as much as racial differences in biology. ${ }^{26}$ Cardiovascular diseases (CVD), such as hypertension and myocardial infarction, are well known to be related to COVID-19 mortality and its complications. In addition to those comorbidities, the outcome is compounded by one's socioeconomic status and even local community. ${ }^{27}$ Among the various minority population groups, black men have the highest overall death rate from CVD, which extends to black women, whose death rates from CVD are higher than those of white women. ${ }^{28}$ In addition, individuals of Hispanic or Latino ancestry in the USA have the highest incidence of nonalcoholic fatty liver disease. ${ }^{29}$

International evidence has shown that marginalized groups are much more likely to be infected and subsequently die from COVID-19. ${ }^{30}$ Three groups have disproportionately suffered the health burden: ethnic minorities; the socioeconomically disadvantaged; and the elderly. ${ }^{31}$ The first two groups are highly prevalent in Brazil, inflating the socioeconomic challenge in our country, making it even more vulnerable to the current phenomenon. ${ }^{32,33}$

The COVID-19 pandemic has evidenced a well spread phenomenon. Social inequity is a fact of the modern world, a consequence of wealth imbalance, and has recently become even deeper in our society. The current pandemic has only shown its already multifactorial disastrous effects on humankind. (Figure 1)
- Housing Characteristics.
- Basic public services (drinkable
water, garbage management). water, garbage management).
. Distance to Health Care Services.

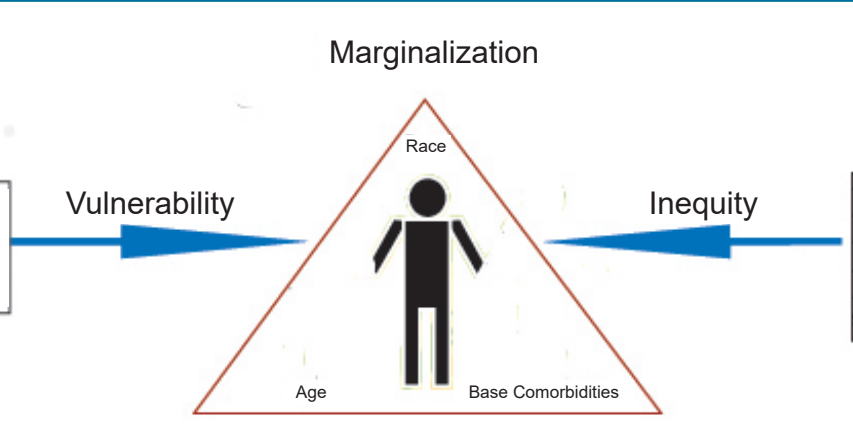

Social Dynamics

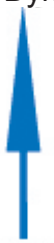

- General Lockdowns.

Public transportation restrictions.

- Low availability of basic supplies.

Social distancing impact on work environment.

Figure 1 - With the patient's characteristics in the center (race, age, and baseline comorbidities), it is illustrated how the external socioeconomic dynamics interacts in the individual, potentially influencing the outcome in COVID-19. 
As with every crisis, we have the opportunity to learn. The world's biggest challenge today is not only to fight back the virus, but to better understand our particular conditions as humans. We have to fight as one, and we must recognize that social inequity not only destroys the most vulnerable members of our society but helps make our society more primitive.

The COVID-19 has managed to threaten the very existence of our society as we know it today, but the real risk behind the pandemic is the social illness. Marginalization, inequity, and racism are the real threats, and they require immediate attention and solutions. To have better results, let us not wait the next pandemic to start tackling the real issues affecting us globally. It is time to lose our chains!

\section{Author Contributions}

Conception and design of the research: Rendon AFV, Volschan IM, Oliveira GMM. Acquisition of data: Rendon AFV, Volschan IM, Pereira MN, Pimentel AF, Monteiro WL, Oliveira GMM. Analysis and

\section{References}

1. COVID-19 Dashboard by the Centre for Systems cience and Engineering (CSSE)Johns Hopkins University [Internet]. Coronavirus Resource Center. [citado30 dez 2020]. Disponível em: h https://Coronavirus.Jhu.edu/map.Html

2. Berwick DM. Choices for the "New Normal." JAMA. 2020;323(21):2125-6. DOI:10.1001/jama.2020.6949

3. Jones J, Sullivan PS, Sanchez TH, Guest JL, Hall EW, Luisi N, et al. Similarities and differences in COVID-19 awareness, concern, and symptoms by race and ethnicity in the United States: cross-sectional survey. J Med Internet Res. 2020;22(7):e20001. DOI:10.2196/20001

4. The World Bank. People, pathogens and our planet. Report number 69145-GLB; 2012. (The Economics of One Health; 2).

5. Tandon P. COVID-19: impact on health of people \& wealth of nations. Indian J Med Res. 2020;151(2-3):121-3. DOI:10.4103/ijmr.IJMR_664_20

6. Hebert PL, Sisk JE, Howell EA. When does a difference become a disparity? conceptualizing racial and ethnic disparities in health. Health Aff (Millwood). 2008;27(2):374-82. doi:10.1377/hlthaff.27.2.374

7. Nunes J. The COVID-19 pandemic: securitization, neoliberal crisis, and global vulnerabilization. Cad Saude Publica. 2020;36(5):e00063120. DOI:10.1590/0102-311x00063120

8. Pereira M, Oliveira AM. Poverty and food insecurity may increase as the threat of COVID-19 spreads. Public Health Nutr. 2020;23(17):3236-40. DOI:10.1017/S1368980020003493

9. Hendl T, Chung R, Wild V. Pandemic surveillance and racialized subpopulations: mitigating vulnerabilities in COVID-19 Apps. J Bioethical Inq. 2020;17(4):829-34. DOI:10.1007/s11673-020-10034-7

10. Mahler, DG, Lakner C, Aguilar AC, Wu H. The World Bank: The impact of COVID-19 (Coronavirus) on global poverty: Why Sub-Saharan Africa might be the region hardest hit. [citado $30 \mathrm{dez} 2020]$. Disponível em: https://blogs.worldbank.org/opendata/impact-covid-19-coronavirusglobal-poverty-why-sub-saharan-africa-might-be-region-hardest interpretation of the data: Rendon AFV, Volschan IM, Pereira MN, Pimentel AF, Monteiro WL, Oliveira GMM. Writing of the manuscript: Rendon AFV, Volschan IM, Pereira MN, Pimentel AF, Monteiro WL, Oliveira GMM. Critical revision of the manuscript for intellectual content: Rendon AFV, Volschan IM, Pereira MN, Pimentel AF, Monteiro WL, Oliveira GMM.

\section{Potential Conflict of Interest}

No potential conflict of interest relevant to this article was reported.

\section{Sources of Funding}

There were no external funding sources for this study.

\section{Study Association}

This article is part of the thesis of Cardiology master in Science submitted by Andres Felipe Valencia Rendon, from Universidade Federal do Rio de Janeiro.

11. Clark E, Fredricks K, Woc-Colburn L, Bottazzi ME, Weatherhead J Disproportionate impact of the COVID-19 pandemic on immigrant communities in the United States. PLoSNegl Trop Dis. 2020;14(7):e0008484. DOI:10.1371/journal.pntd.0008484

12. Wadhera RK, Wadhera P, Gaba P, Figueroa JF, Maddox KEJ, Yeh RW, et al. Variation in COVID-19 hospitalizations and deaths across New York City Boroughs. JAMA. 2020;323(21):2192-5. DOI:10.1001/jama.2020.7197

13. Miller MJ, Loaiza JR, Takyar A, Gilman RH. COVID-19 in Latin America: novel transmission dynamics for a global pandemic? PLoS Negl Trop Dis. 2020;14(5):e0008265. DOI:10.1371/journal.pntd.0008265

14. Abrams EM, Szefler SJ. COVID-19 and the impact of social determinants of health. Lancet Respir Med. 2020;8(7):659-61. DOI:10.1016/S22132600(20)30234-4

15. Chaves M, Silva CL. Uma avaliaçao do sistema único de saude nas capitais brasileiras: sugestoes para a criaçao de politicas publicas. JGCG. 2018;12(3):49-63.

16. Pêgo B, Moura R, Nunes M,Krüger C, Moreira P, Ferreira G, et al Pandemia e fronteiras brasileiras: análise da evolução da Covid-19 e proposições. Dirur, Diretoria de Estudos e Politicas Regionais, Urbabas e Ambientais. 2020(16):68.

17. Ponce D. The impact of coronavirus in Brazil: politics and the pandemic Nat Rev Nephrol. 2020;16(9):483. DOI:10.1038/s41581-020-0327-0

18. Candido DS, Claro IM, Jesus JG, Souza WM, Moreira FRR, Dellicour S, et al. Evolution and epidemic spread of SARS-CoV-2 in Brazil. Science. 2020;369(6508):1255-60. DOI: 10.1126/science.abd2161

19. Brant LCC, Nascimento BR, Teixeira RA, Lopes MACQ, Malta DC, Oliveira GMM, et al. Excess of cardiovascular deaths during the COVID-19 pandemic in Brazilian capital cities. Heart. 2020;106(24):1898905. DOI:10.1136/heartjnl-2020-317663 
20. Susan Dodds WR. Why bioethics needs a concept of vulnerability. Int J Fem Approaches Bioeth. 2012;5(2):11. DOI:10.3138/ijfab.5.2.11

21. Rogers W, Ballantyne A. Special populations: vulnerability and protection. R Eletr Com Inf Inov Saúde. 2008;2(Suppl 1):31-41. DOI:10.3395/reciis.v2.Sup1.207en

22. Acharya R, Porwal A. A vulnerability index for the management of and response to the COVID-19 epidemic in India: an ecological study. Lancet Glob Health. 2020;8(9):e1142-51. DOI:10.1016/S2214-109X(20)30300-4

23. The Lancet. Redefining vulnerability in the era of COVID-19. Lancet. 2020;395(10230):1089. DOI:10.1016/S0140-6736(20)30757-1

24. Gray DM, Anyane-Yeboa A, Balzora S, Issaka RB, May FP. COVID-19 and the other pandemic: populations made vulnerable by systemic inequity. Nat Rev Gastroenterol Hepatol. 2020;17(9):520-2. doi:10.1038/ s41575-020-0330-8

25. Ahmed F, Ahmed N, Pissarides C, Stiglitz J. Why inequality could spread COVID-19. Lancet Public Health. 2020;5(5):e240. DOI:10.1016/ S2468-2667(20)30085-2

26. American College of Physicians. Racial and Ethnic Disparities in Health Care, Updated 2010. Philadelphia: American College of Physicians; 2010.
27. Graham G. Disparities in cardiovascular disease risk in the United States. Curr Cardiol Rev. 2015;11(3):238-45. DOI:10.2174/157340 3X11666141122220003

28. Mensah GA, Mokdad AH, Ford ES, Greenlund KJ, Croft JB. State of disparities in cardiovascular health in the United States. Circulation. 2005;111(10):1233-41. DOI:10.1161/01.CIR.0000158136.76824.04

29. Khazanchi R, Evans CT, Marcelin JR. Racism, not race, drives inequity across the COVID-19 continuum. JAMA Netw Open. 2020;3(9):e2019933. DOI:10.1001/jamanetworkopen.2020.19933

30. Adhikari S, Pantaleo NP, Feldman JM, Ogedegbe O, Thorpe L, Troxel AB. Assessment of community-level disparities in coronavirus disease 2019 (COVID-19) infections and deaths in large US metropolitan areas. JAMA Netw Open. 2020;3(7):e2016938. DOI:10.1001/jamanetworkopen.2020.16938

31. Ali S, Asaria M, Stranges S. COVID-19 and inequality: are we all in this together? Can J Public Health. 2020;111(3):415-6. DOI:10.17269/s41997020-00351-0

32. Williams DR, Cooper LA. COVID-19 and health equity-a new kind of "herd immunity". JAMA. 2020;323(24):2478-80. DOI:10.1001/jama.2020.8051

33. Swift R. COVID-19 \& Minority Health Access. Infec Dis Insights. 2020 Mar;8:1-7. 